\title{
The straitjacket at workplace: Mobbing
}

\author{
Müberra Yüksel \\ (Department of Advertising, Faculty of Communication, Kadir Has University, Istanbul 34083, Turkey)
}

\begin{abstract}
Mobbing has been defined as a chronic asymmetric pattern of power relations and a consequent conflict transformed into a systematic discrimination or mistreatment at workplace which is expressed through unethical or aggressive communication (Leynman, 1996). Mobbing occurs when an employee in the workplace is steadily subjected to aggressive behavior from more than one colleague or supervisor over a period of time, in a situation where the target finds it difficult to defend him/herself to escape this dire situation. Such a long term incivility tends to stigmatize the mobbed victim and may cause severe psychological trauma since (s)he is metaphorically in a straitjacket. In this double-bind and double-squeeze condition where (s)he can neither get out of the situation nor endure the ordeal, a positive outcome is unlikely. How do we differentiate mobbing from conflict in organizations and how are disputes converted into mobbing behavior, and if one may even do research on mobbing in a culture of "organizational silence" and "obedience/submission" in a developing country will be the first theoretical research question. Whether systemic silence as a collective level phenomenon is not only an obstacle to healthy organizational communication and relationships, but also a serious barrier to development, participation and learning from malpractices is another relevant question. Most researches investigating the background of mobbing are based on either experiences of targets as victims or the critical cases including the perpetrators as mobber; Therefore, the findings are often at individual level and subjective. They are often "ex post facto" analysis of psychological dimensions (e.g., personality characteristics of mostly of mobbed victims and rarely of mobbers) or legal dimensions. There are few "ex ante" analyses of organizational culture dimensions so that preventive measures may be taken prior to any serious mobbing case is reported. This paper's objective is to approach mobbing as a function of group conflict and rumor that is uncontrolled for a long time. By exploring the background of mobbing in ten companies from service sector in Istanbul-Turkey, this view is assessed. The findings confirmed that mobbing is a function of relational conflict and gossip particularly in companies with high positional power distance and highly centralized decision-making where high power imbalance between supervisors and subordinates are salient. Such organizations seem to be more conducive to concealed mobbing and survival than to development and participation of employees as "modus operandi".
\end{abstract}

Key words: mobbing; organizational conflict; organizational culture; spiral of silence and rumor

\section{Introduction}

\subsection{Definition of workplace mobbing}

Mobbing has been defined as a chronic asymmetric pattern of power relations and a consequent conflict transformed into a systematic discrimination or mistreatment at workplace which is expressed through unethical or aggressive communication and behavior (Leynman, 1996). While mobbing has both psychological and legal

Müberra Yüksel, Ph.D., assistant professor, Department of Advertising, Faculty of Communication, Kadir Has University; research fields: human resource management, management \& organization, conflict management. 
implications, it is a problematic concept related with organizational culture and socialization process, which is based on norms as well as perceptions of employees.

Mobbing is different from bullying since it is not limited to dyadic individual behavior, and it is an asymmetric pattern of political behavior leading to "psychological terrorization" in the workplace that often ends up in traumatization according to Leynman (1996, pp.165-184). Although the two terms are often used interchangeably in the literature, the legal definition by the ILO also states that mobbing is qualified as below (Öke \& Yücetürk, 2005):

"Offensive behavior through vindictive, cruel, malicious or humiliating attempts to undermine an individual or groups of employees.... It involves ganging up on or "mobbing" a targeted employee and subjecting that person to psychological harassment. Mobbing includes constant negative remarks or criticisms, isolating a person from social contacts and gossiping or spreading false information".

The mobbing actions occur on a frequent basis (at least once a week) and over a long period of time (at least six months' duration). The main distinction between "conflict" and "mobbing" is that the latter does not focus on what is done or how it is done, but rather on the frequency and duration of whatever is done (Leymann \& Gustafsson, 1996, pp.251-275). In a nutshell, mobbing is an unmanaged protracted conflict and consequent rumor through grapevine that is distorted over time and turned into a psychological terror at work environment. Leymann has underlined mobbing as a five phased process with three levels:

(1) It often starts with a critical conflicting issue initially in a dyadic relationship;

(2) Aggressive behavior and psychologically indecent gossips trigger political dynamics at work;

(3) Management that is often indirectly involved, either misinterprets or misjudges the situation, in this negative cycle of chain of events or patterns of behavior against the mobbed employee;

(4) Labeling or stigmatizing the victim;

(5) Either makes the victim ill through mental fatigue or pushes him/her leave the job.

This process is generally perceived at three levels with due regards to the symptoms:

(1) The target either resists or avoids at the early conflict stage and is rehabilitated through rotation or some other means;

(2) The victim becomes ill and often is absent from work due to post-traumatic stress disorders;

(3) Eventually the victim has to quit the job (Leynman, 1996).

Meanwhile, the ILO resolution concerning prevention of grievances, which was adopted in 2001, describe the forms of harassment similar to the above.

\subsection{Organizational culture and indicators of workplace mobbing}

Following Salin (2003) and Leynman (1996), who has proposed a model based on three clusters, the author also emphasize the organizational culture as a breeding ground for negative attitudes that are mobbing antecedents. Mobbing is often a repeated pattern of interaction between structures and processes from work groups in organizations. Conditions in themselves seldom lead to mobbing, but act as the enabling factors when there are additional motivator or trigger factors: Disabling structures and processes of participation or production (e.g., power imbalance, low perceived costs of mobbing, dissatisfaction and frustration with the work environment, triggering circumstances, such as restructuring and crises, organizational changes, changes in work groups, excessive hierarchy and centralization).

The abuse of individual targets in mobbing often includes the following types of behavior:

(1) Punishing others for being competent (higher than average performance); 
(2) Refusing to delegate or dumping overloading with work and shortening the deadlines;

(3) Persistently picking on people in front of peers;

(4) Keeping individuals in their place by blocking their promotion;

(5) Feeling envious of others' professional or social ability; Thereafter setting out to make them appear incompetent in the hope of getting them dismissed or making them resign through "constructive dismissal" (Öke \& Yücetürk, 2005).

Table 1 Mobbing indicators

\begin{tabular}{|c|l|}
\hline 1 & By standard criteria of job performance, the target is at least average, probably above average. \\
\hline 2 & Rumors circulate about the target's misdeeds: "Did you hear what she/ he did last week?" \\
\hline 3 & The target is not invited to meetings or voted for committees, is excluded or excludes self. \\
\hline 4 & Collective focus on a critical incident that "shows what kind of person (s)he really is." \\
\hline 5 & Shared conviction that the target needs some kind of formal punishment, "to be taught a lesson." \\
\hline 6 & Unusual timing of the decision to punish, e. g., apart from the annual performance review. \\
\hline 7 & Emotion-laden, defamatory rhetoric about the target in oral and written communications. \\
\hline 8 & Formal expressions of collective negative sentiment toward the target. \\
\hline 9 & High value on secrecy, confidentiality, and collegial solidarity among the group of mobbers. \\
\hline 10 & Loss of diversity of argument, so that it becomes dangerous to defend the target. \\
\hline 11 & The adding up of the target's real or imagined sins to make a fatal sin that cries for action. \\
\hline 12 & The target is seen as repulsive, with no positive qualities; stigmatizing, exclusionary labeling. \\
\hline 13 & Disregard of established procedures, as mobbers take matters into their own hands. \\
\hline 14 & Resistance to independent, outside review of sanctions imposed on the target. \\
\hline 15 & Outraged response to any appeals for outside help the target may make. \\
\hline 16 & Mobbers' fear of violence from target, visa versa or both. \\
\hline
\end{tabular}

Data source: $L I P T=$ Leymann Inventory of Psychological Terrorization; $N A Q=$ Negative Acts Questionnaire.

Thus, the operational indicators suggested by Leynmann is in line with the prevention regulation of ILO (2001) such as: Measures to exclude or isolate a target from professional activities, persistent negative attacks on personal or professional performance without reason or legitimate authority, manipulation of a targeted person's personal or professional reputation by rumor, gossip and ridicule, abusing a position of power by persistently undermining a targeted person's work, or setting objectives with unreasonable and/or impossible deadlines, or unachievable tasks, inappropriate monitoring of a targeted person's performance, unreasonable and/or unfounded refusal of leave and training.

Overall, Salin (2003) also indicates that the antecedents act as a filter, making the environment prone to mobbing. Understanding the causes of mobbing, finding preventive solutions and highlighting the rights and responsibilities of employees at workplace are becoming increasingly significant within developing countries, particularly during crisis periods. In Turkey, a labor law concerning mobbing has come recently on the agenda, and only a couple of incidents have turned into a lawsuit. However, where most employees play the three monkeys (being deaf, blind and mute) during the formal events or gossiping to fill in "the white space" in informal communication, mobbing is anticipated to be either hidden or indirect at workplace.

\subsection{Literature review on empirical research on workplace mobbing}

"Lies gallop, while truth strolls step by step. Yet, all the time truth is on time."

$$
\text { -A Japanese proverb }
$$


Numerous scholars have contributed the literature of mobbing as a main criterion of occupational health. Research has shown that mobbing is a very widespread phenomenon, and it has been estimated that approximately $10 \%$ of the European Union workers are victims of workplace bullying or mobbing (Ferrari, 2004). Mobbing has been described as a hostile and unethical communication systematically directed by more than one individual, mainly toward one individual, who is pushed into a helpless and defenseless position by persistent actions (Leymann, 1996). These negative behaviors occur at least once a week and over a long time, at least six months. These acts include verbal aggressions, criticism, rumors, humiliations, etc.. In a broad sense, persistent acts that placed the targeted victim in a disadvantaged position or social standing at work. Those behaviors may be very different activities, used with the aim of persistently humiliating, intimidating, frightening or punishing the victims, so that they will eventually decide to leave their work (Zapf \& Einarsen, 2001).

Constant exposure to the above mentioned situations has been linked to a variety of negative health effects in the victim and also has been associated with absenteeism, turnover and higher intent for resignation or to application for early retirements (Leymann, 1996). Leynman used the terror to describe the intense, debilitating fear that comes from being subjected to repeated acts of aggression in the workplace, feeling helpless to defend oneself and wondering when the next attack will come. He also highlighted the toxic nature of fear and anxiety making workplace counterproductive.

The relationship between mobbing and absenteeism has been confirmed by a number of studies. For instance, it was found in a Finnish study of hospital employees that the targets of mobbing had on average a 50\% higher sickness and absenteeism than those who were not mobbed. High numbers were reported by $30 \%$ of victims reporting sickness absence more than 30 days due to mobbing in Norway as well. They have also found that self-labeling approach gave a much more conservative estimate of mobbing than operational criteria (Nielsen, et al., 2009, pp.81-101).

Some studies have identified personality traits as key factors to explain mobbing processes. In contrast to these research, Leymann (1996) has shown three organizational factors as essential sources in the development of mobbing: (1) culture and structure of organization, (2) a poor conflict management and (3) a poor formal communication. From this point of view, conflicts are common situations in the workplace. However, managers must take responsibility to manage conflict and hearsay (since grapevine control in informal communication is important), management is at the crux of the matter within this context. Thus, the conditions of the organizational context may make possible, easier or even might promote mobbing.

By and large, mobbing is a process of deliberate scapegoating in the workplace. The communication patterns and channels or even the leadership styles may sometimes legitimate the mobbing activities. One step further, Zapf (1999) has stated that it is possible, in a statistical sense, to consider the organization as the cause of mobbing, which is an unresolved escalated conflict; And if various organizational circumstances like continuous rumors contribute to the total number of conflicts, the number of unresolved conflicts will increase leading to a higher number of mobbing cases.

Another approach has been elaborated by Liefooghe and Olafsson (1999), who explore people's representations of mobbing at work and analyze the individual and organizational factors that are believed to influence these processes. Their framework allows us to interpret the objective realities at cultural, organizational, and individual levels. Mikkelsen and Einarsen (2001) have questioned the assumption that a generally poor work environment that lack conflict management contributes to mobbing or bullying by comparing mobbed employees responses with the rest of the employees. They still suggest that management style and pattern of behavior may 
have some impact on the extent of mobbing.

Other research on self-reported victimization in Europe reveal variations - the least being less than 5\% in Scandinavian countries (Nielsen, et al., 2009), and the most 55\% in Turkey (Bilgel, Aytaç \& Bayram, 2005). Other studies reveal the fact that gossip culture and covert uncivil actions may directly cause mobbing (Baillien, et al., 2005). There is also research testing the premise that collectivism and uncertainty avoidance or risk aversion in the workplace is associated with lower levels of incivility (Wu, et al., 2009, pp.164-185). As demonstrated in Fig.1, Einarsen also highlights the role of context - the organizational culture and climate with reference to workplace mobbing.

There are variations in the amount of recognition of mobbing as a problem and its negative impact on individual employees and workplace productivity. Empirically, there is not enough research on mobbing in Turkey, and most studies are from developed countries where mobbing has been a growing source of concern.

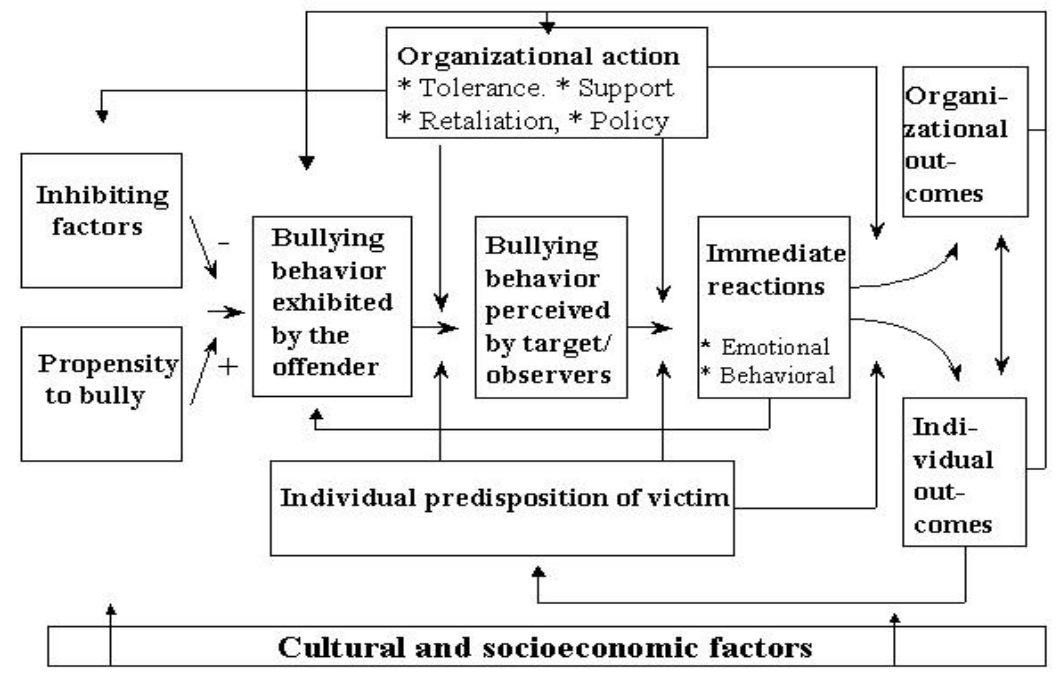

Fig. 1 The conceptual model of workplace mobbing with organizational culture emphasis

Data source: Einarsen, 2005.

Bilgel, Aytac and Bayram (2004) carried out a survey among 944 full time public employees working in education, health and security in Turkey. According to the findings, the majority of respondents (79.5\%) who experienced of mobbing at work reported to have experienced symptoms of anxiety. The survey also found statistically significant differences between mobbed and unexposed employees (treated as a control group) in terms of depression and job-induced stress (Bilgel, Aytac \& Bayram, 2004) similar to the findings in Europe (Agervold \& Mikkelsen, 2004).

Although there are some studies from legal standpoint on normative grounds (Öke \& Yücetürk, 2005), there are few studies on mobbing and bullying in Turkey from cultural standpoint. Linking the findings of Geert Hofstedte's (1996) studies to see if power distance, collectivism, gossip culture, low context versus high context communication have impact on mobbing and understanding, if prolonged conflicts and unmanaged gossip pave the way for workplace mobbing within the context of "spiral of silence" is at the crux of this study. How are disputes converted into mobbing behavior and if one may even do research on mobbing in a culture of "organizational silence" and "obedience/submission" in Turkey is the major theoretical research question. 


\section{Methodology}

The aims of this research project are analyze the relationships between organizational culture and mobbing in the workplace, and identify the features of that culture, considered as specific risk factors which facilitate the mobbing processes development (beliefs, values, specific practices, etc.). In this frame, the author has used a simple questionnaire to assess the perception of the organizational culture, management, members of prevention services, etc., and the main contents in the perception of enabling and disabling factors by the employees.

When the motivating internal competitions and/or precipitating structures are present, the enabling conditions will affect whether mobbing is possible or not in a specific organization. The empirical model employed here adapts the one developed by Salin (2003a) who pays special attention to the cultural dimension of the structures and processes of the organization.

\subsection{Qualitative analyses and findings}

In this exploratory research, the author made in-depth structured interviews with about twenty human resource (HR) managers who are experienced in preventing or handling mobbing as organizational insiders and/or managers in ten companies of convenience sample. Then, the author conducted an anonymous survey in one media company where 77 employees out of 219 responded the questionnaire.

During the face-to-face interviews, while almost half of the HR managers have heard about mobbing lately and admitted that they have no preventive policies, they were all aware of the issue. Since mobbing is not a preferable topic, objective and hypothetical questions are also posed to find out about the likelihood of positions of mobbers. They all mentioned gossip and conflict as the main areas of concern. Almost all companies had either training or coaching on conflict management, none of the managers regarded managing rumors as a possibility, despite the fact that most of them defined mobbing either as a communication problem or as a lack of trust problem.

The trust issue is taken both as an interpersonal and as a cultural issue since most managers stated the fact that in Turkey the trust level is generally low. Most of them did not distinguish bullying from mobbing, and more than half of them perceived mobbing, as a personality problem of both the perpetuators and the victims. They agreed upon the fact that the context might be conducive, too. When an hypothetical question is asked about who might initiate mobbing, most responded as superiors, some mentioned peers. One might infer upon that subordinates are perceived to be the most likely target. As for organizational structure, seven out of ten companies had centralized decision-making and the position of HR managers as staff position along with their hierarchical middle position, and gave them less leverage in policy-making.

Although none of the HR managers admitted critical incidents or cases of mobbing in their organization, they all accepted most of the indirect behaviors of mobbing as a possible attitude or conduct problem of employees, and stated that sometimes they had such grievances. As for the direct and blatantly offensive acts of mobbing such as stigmatizing based on primary or secondary differences, they mentioned that no colleague would acknowledge such misconduct since everybody including bystanders would lose face in the organization, particularly in their work group.

High power distance and organizational culture of roles dominates in most of the selected companies. All HR managers stated that the most important thing in their companies was to comply with the established rules, procedures and standards. Moreover, although they mentioned teamwork as a significant competency, they implied that cross-functional teamwork is rarely practiced. Further, procedures like whistle-blowing policy are not 
included among their codes of conduct, despite the fact that corporate citizenship (or corporate social responsibility) is on their agenda. Nevertheless, companies and their human resource management take into account of issues about conflict and mobbing under various policies and codes of conduct concerning rights and responsibilities pertaining to participation and communication.

\subsection{Quantitative analyses and results}

The questionnaire was developed based on the prior empirical research employing negative indicators (see Table 1) and adapted according to our preliminary findings from the interviews. Through indirect negative indicators, examining the extent of mobbing and the cultural antecedents of mobbing among respondents were aimed. The participants were requested to complete a questionnaire with 25 questions comprising of 2 sections.

The first section was about the demographic characteristics of the respondents (e.g., gender, age, position, tenure); The second section included a series of questions on the three aspects of mobbing such as social isolation, extreme demands and discrediting dimensions like negative gossiping along with a few questions that indirectly address mobbing. A few open-ended check questions are either about the general climate of the organization as is or are hypothetical questions on mobbing such as "what do you think are the root causes of mobbing" (if your colleague was facing such a situation). The five Likert scale between "none to often" is employed for all other questions.

The results showed that teamwork was not practiced much. Only $28 \%$ respondents stated that the teamwork is practiced in decision-making or production in their companies. Even these findings are thought-provoking since organizational structures are being transformed into multifunctional teams of flexibility and connectivity with globalization. In sum, $23 \%$ of respondents withheld necessary information from their colleagues, subordinates or supervisors. Almost half of the respondents (48\%) reported malicious gossip at workplace. Among mobbing acts were: Being given meaningless tasks or extreme deadlines or workload (43\%) was among the top. Manifest misdemeanor (9\%) and social isolation (12\%) was observed less as compared with limitations to use days off (38\%), the latter might be an end result of micromanagement of superior. Although not many labeled themselves as being mobbed or mobber (2\%), still operational indicators revealed workplace mobbing is a fact of relational power. When asked have you ever witnessed mobbing at your workplace, the answer is $49 \%$ "yes" in an organizational culture of spiral of silence.

Based on the data received from the research, it was determined that there is high level of readiness of employees to take part in the organizational preventive mechanism of mobbing, since they responded that they would keep silent if they had faced mobbing. Answering the question: "Would you agree to take part in the process of preventive trainings on conflict and gossip management so that you will improve your diagnosis and coping skills for counteraction for mobbing", $78 \%$ of respondents said "yes", while $22 \%$ said "no". When asked if they would like have an anti-mobbing policy and relevant codes of conduct, only $9 \%$ said "no". Since both organizations and employees have been facing numerous additional problems lately during global economic crisis, such organizational procedures, interventions and norms become necessary.

\section{Conclusion and discussion}

\subsection{Conclusion}

On the whole, these companies are characterized by an unbalanced distribution of power, because $83 \%$ respondents stated that the power asymmetry and power distance is rather high. This implies hierarchical structure 
and centralization in decision making, which is contradicting with the contemporary trends in organization design, while it also is a context conducive to mobbing.

The goal of the research was to determine how managers and employees perceive the mechanisms of misuse of power, gossip, conflict that would lead to mobbing. Finally, based upon the empirical findings, the author probed into conceptual underpinnings and relevance between mobbing and conflict/gossip management in order to see if employees or organizations may at least prevent or cope with mobbing. By determining the cultural and organizational context of mobbing, the aim here is to recognize the mobbing dynamics such as communication patterns of interaction and cultural factors of companies in a developing country, so that more research may be done for detailed policy implications and implementation.

\subsection{Discussion: Mobbing might become the invisible heavy hand of organizations}

"We shall never cease from exploration

And the end of all our exploration

Will be to arrive where we started

And know the place for the first time."

-T. S. Eliot

There are limitations of this study since this is almost a first cut into mobbing in Turkey. A cross-sectional snapshot of mobbing qualitatively will first pave the way for quantitative analysis of a larger sample. Right now, this study is mostly descriptive and exploratory, yet, this limitation will not hinder the possible discovery that mobbing in a developing context has both particular and universal aspects. Further studies can probe into the details of the differences of antecedents of mobbing in developing versus developed countries and divergent policies or practices.

For instance, while organizational silencing might also demand transformation of culture and structure of organization along with preventive policies and training, in an organizational culture where whistle blowing and other democratic rights of employees are appropriate, solely preventive policies and training which will enhance awareness and responsibility would suffice. Another inference is to have an interdisciplinary research on mobbing and gossip management particularly in developing countries where accommodating conflict style is preferred and silencing is often chosen rather than voicing negative or difficult issues.

\section{References:}

Agervold, M. \& Mikkelsen, E. G.. (2004). Impact of psyhosocial work environment on registerd absence from work: A two-year longitudinal study using the IPAW cohort. Work \& Stress: A Journal of Work, Helath \& Organizations, 18(4), 323-326.

Baillien, E., Neyens I., De Witte, H. \& Cuyper, N.. (2009). A qualitative study on the development of workplae bullying: Towards a three way model. Journal of Community and Applied Social Psychology, 19, 1-16.

Baillien, E., Neyens I. \& De Witte, H.. (2005). Task, team and organizational risk factors for mobbing at work: A qualitative study. In: Avallone, F., Sinangil, H. K. \& Caetano, A. (Eds.), Convivence in organizations and society. Milano: Guerini Studio. 12, 217-225.

Bilgel, N., Aytaç, S. \& Bayram, N.. (2006). Bullying in Turkish white-collar workers. Occupational Medicine, 56(4), $226-231$.

Black, R. J.. (2003). Organizational culture: Creating the influence needed for strategic success. London, UK.

Bultena, C. D. \& Whatcott, R. D.. (2008). Bushwacked at work: A comparative analysis of mobbing and bullying at work. Proceedings of ASBBS, 15(1), 652-666.

D'amato, A. \& Zijlstra, F. R. H.. (2008). Psychological and organizational climate research: Contrasting perspectives and research traditions. European Journal of Work and Organizational Psychology, 17(1), 1-5.

Davenport, N., Schwartz, R. D. \& Eliot, G. P.. (1999). Mobbing: Emotional abuse in the American workplace ames. Iowa: Civil Society Publishing.

Einarsen, S.. (1999). The nature and causes of bullying at work. International Journal of Manpower, 20(1/2), 16-27. 
Einarsen, S., Hoel, H., Zapf, D. \& Cooper, C. L.. (2003). Bullying and emotional abuse in the workplace: International perspectives in research and practice. London/New York: Taylor \& Francis.

Ferrari, E.. (2004). Raising awareness on mobbing: An EU perspective. DAPHNE program, European Commission, April.

Hoel, H., Cooper, C. \& Faragher, B.. (2001). The experience of bullying in great Britain: The impact of organizational status. European Journal of Work and Organizational Psychology, 10(4), 443-465.

Hofstede, G.. (1991). Cultures and organizations, software of the mind. New York: McGraw-Hill.

Howard, P. J. \& Jane, M. Kotter, J.. (1992). Corporate culture and performance. New York: Free Press.

Islamoğlu, G., Birsel, M. \& Börü, D.. (2007). Kurum Icinde Guven. Istanbul: Inkilap.

Lee, C., Pillutla, M. \& Law, K. S.. (2000). Power-distance, gender and organizational justice. Journal of Management, 26(4), 685-705.

Leymann, H. \& Gustafsson, A.. (1996). Mobbing at work and the development of post traumatic stress disorders. European Journal of Work and Organizational Psychology, 5(2), 251-275.

Leymann, H.. (1996). The Content and development of mobbing at work. European Journal of Work and Organizational Psychology, 5(2), 165-184.

Liefooghe, A. P. D. \& Olafsson, R.. (1999). "Scientists" and "amateurs": Mapping the bulling domain. International Journal of Manpower, 20(1/2), 39-49.

Wu, L., Shu-Cheng Steve Chi, Friedman R. \& Ming-Hong Tsai. (2009). Explaining Incivility in the workplace: The effects of personality and culture. Negotiation and Conflict Management Research, 2(2), 164-184.

Lutgen-Sandvik, P., Tracy, S. J. \& Alberts, J. K.. (2007). Burned by bullying in the American workplace: Prevalence, perception, degree and impact. Journal of Management Studies, 44(6), 837-862. Retrieved from http://ssrn.com/abstract=1007331.

Mikkelsen, E. \& Einarsen, S.. (2001). Bullying in Danish work-life: Prevalence and health correlates. European Journal of Work and Organizational Psychology, 10(4), 393-414.

Montalbán, F. M. \& Durán, M. A.. (2005, June 1). Mobbing: A cultural approach of conflict in work organizations. IACM 18th Annual Conference. Retrieved from http://ssrn.com/abstract $=735105$.

Moreno-Jimenez, M. A. R. \& Benadero, M. E. M.. (2008). Workplace bullying in southern Europe: Prevalence, forms and risk groups in a Spanish sample. International Journal of Organizational Behavior, 13(2), 95-109.

Nielsen, M. B., Skogstag, A., Maathiesen, S. B., Glaso, L., Aasland, M. S., Notelaers, G. \& Einarsen, S.. (2009). Prevalence of workplace bullying in Norway: Comparisons across time and estimation methods. European Journal of Work and Organizational Psychology, 18(1), 81-102.

Öke, M. K. \& Yücetürk, E. E.. (2005). Mobbing and bullying legal aspects related to workplace bullying in Turkey. South-East Europe Review, 2, 61-70.

Parker, M.. (2000). Organizational culture and identity. London: Sage.

Salin, D.. (2001). Prevalence and forms of bullying among business professionals: A comparison of two different strategies for measuring bullying. European Journal of Work and Organizational Psychology, 10(4), 425-441.

Salin, D.. (2003a). Ways of explaining workplace bullying: A review of enabling, motivating and precipitating structures and processes in the work environment. Human Relations, 56(10), 1213-1232.

Salin, D.. (2003b). Workplace bulling among business professionals: Prevalence, organizational antecedents and gender differences. (Master dissertation, Swedish School of Economics and Business Administration)

Salin, D.. (2006). Organizational measures taken against workplace bullying: The case of Finnish municipalities. (Working Paper No. 521, Swedish School of Economics and Business Administration, Helsinki-Finland).

Tutar, H.. (2004). İş yerinde psikolojik şiddet sarmalı: Nedenleri ve sonuçları, Yönetim Bilimleri Dergisi, T. C. Çanakkale Onsekiz Mart Üniversitesi Bİ̈BF, 92-104.

Vartia, M.. (1996). The sources of bullying-Psychological work environment and organizational climate. European Journal of Work and Organizational Psychology, 5(2), 2003-214.

Zapf, D.. (1999). Organizational work group related and personal causes of mobbing/bullying at work. International Journal of Manpower, 20(1/2), 70-85.

Zapf, D. \& Leymann, H. (Eds.). (1996). Mobbing and victimization at work (Special Issue). European Journal of Work and Organizational Psychology, 5(2), 215-237.

Zapf, D. \& Einarsen, S. (Eds.). (2001). Bullying in the work place (Special Issue). European Journal of Work and Organizational Psychology, 10(4), 369-528.

Zapf, D. \& Einarsen, S.. (2003). Individual antecedents of bullying: Victims and perpetrators. In: Einarsen, S., Hoel, H., Zapf, D. \& Cooper, C. L. C. (Eds.), Bullying and emotional abuse in the workplace: International perspectives in research and practice. London: Taylor \& Francis Books Ltd.

(Edited by Ruby and Chris) 